\title{
PARÂMETROS GENÉTICOS DO RENDIMENTO DE GRÃOS E SEUS COMPONENTES COM IMPLICAÇÕES NA SELEÇÃO INDIRETA EM GENÓTIPOS DE FEIJÃO PRETO
}

\author{
GENETIC PARAMETERS OF GRAIN YIELD AND ITS COMPONENTS WITH \\ IMPLICATIONS IN THE INDIRECT SELECTION OF BLACK BEAN GENOTYPES
}

\section{Jefferson Luís Meirelles Coimbra ${ }^{1}$ Altamir Frederico Guidolin ${ }^{2}$ Fernando Irajá Felix de Carvalho ${ }^{3}$}

RESUMO

Trinta e dois genótipos de feijão preto (Phaseolus vulgaris L.) foram avaliados a campo, no ano agrícola de 1996/97 em Lages/SC. Foi medida a influência de três caracteres de importância agronômica sobre o rendimento de grãos por unidade de área. $O$ experimento foi conduzido no delineamento experimental de blocos casualizados, com quatro repetições. $O$ objetivo do trabalho foi estimar parâmetros genéticos e fenotípicos. A seleção direta revelou valores de ganhos genéticos superiores aos obtidos através da seleção indireta. O componente do rendimento de grãos que mais contribuiu para o progresso genético, via seleção indireta, foi o peso de mil grãos (PMG), em relação aos componentes, número de legumes por planta $(N L P) e$ o número de grãos por legume (NGL). Os resultados encontrados revelam que os genótipos de feijão preto testados possuem ampla variabilidade genética, indicando serem excelentes fontes de germoplasma. Sendo assim, o emprego das estimativas de parâmetros genéticos como variância genética, entre linhas puras e o coeficiente de herdabilidade no sentido amplo, poderão auxiliar na seleção destes caracteres, constituindo-se numa poderosa ferramenta para os melhoristas de feijão.

Palavras-chave: Phaseolus vulgaris, seleção, cultura, rendimento de grãos.

\section{SUMMARY}

Thirty two genotypes of black bean (Phaseolus vulgaris L.) had their field performance evaluated in the agricultural year of 1996/97 in Lages/SC. The influences of three characters of agronomic importance on the production of grains for unit per area were scored. A completely randomized block design was used with four replications. The objective of the study was to estimate some genetic and phenotypic parameters of black bean. The direct selection revealed values of genetic gains superior to the ones obtained through indirect selection. The weight of a thousand grain (PMG) contributed to genetic progress through indirect selection than, the number of pods per plant (NLP) and the number of grains per pod (NGL). The results demonstrated that the tested black bean genotypes had a wide genetic variability, which was an indication of excellent germplas sources. The employment of estimates of genetic parameters such as genetic variance between pure lines and the heritability coefficient may be used as a powerful tool for bean breeders

Key words: Phaseolus vulgaris, crop, selection, grain yield.

\section{INTRODUÇÃO}

O Brasil é um dos principais produtores e consumidores de feijão (Phaseolus vulgaris L.) no contexto mundial. Juntamente com arroz e milho, o feijão é uma das principais culturas voltadas ao mercado interno, sendo produzido na sua maior parte por pequenos agricultores.

Segundo dados do Instituto Brasileiro de Geografia e Estatística (FUNDAÇÃO, 1988), a cultura do feijão caracteriza-se pelos baixos rendimentos obtidos em lavouras de pequena extensão (56\% são menores que 5 ha). O rendimento de grãos de feijão tem atingido patamares tão baixos que "se não houver uma tomada de decisão para reverter esta situação, em pouco tempo a cultura estará inviabilizada economicamente" (WILDNER, 1992).

\footnotetext{
${ }^{1}$ Engenheiro Agrônomo, estudante do Curso de Pós-graduação em Agronomia, Universidade Federal de Pelotas (UFPel). Pelotas, RS. Bolsista da CAPES

${ }^{2}$ Engenheiro Agrônomo, Mestre, Professor de Genética do Centro de Ciências Agroveterinárias, Universidade do Estado de Santa Catarina (UDESC).

${ }^{3}$ Engenheiro Agrônomo, PhD., Professor da Faculdade de Agronomia, UFPel, Pesquisador do CNPq. Caixa Postal 354, 96001-970, Capão do Leão, RS. E-mail: jlmcpos@ufpel.tche.br. Autor para correspondência.
} 
O rendimento de grãos é um caráter complexo, resultante dos efeitos multiplicativos de seus componentes primários. Diversos processos fisiológicos podem ter influência direta ou indireta sobre o caráter rendimento de grãos (FEHR, 1987). A participação do Rio Grande do Sul na produção brasileira de feijão decresceu nos últimos 15 anos, deslocando o Estado no âmbito nacional de $3^{\circ}$ para $7^{\circ}$ produtor (JOBIM, 1990). Uma das alternativas para contornar esta situação seria intensificar os programas de melhoramento genético da espécie, na busca de genótipos mais produtivos e ajustados às condições de ambiente da região Sul. Sendo assim, a existência de variabilidade genética torna-se condição essencial para o melhorista poder exercer uma pressão de seleção artificial e alcaçar progresso através da obtenção de genótipos superiores. Além da variabilidade genética, é necessário que se conheça o grau de relação genética entre a planta-mãe e suas progênies, estimado através da herdabilidade, permitindo ao melhorista estabelecer uma relação adequada com os objetivos a serem alcançados no programa de melhoramento genético de plantas (CARVALHO, 1981).

$\mathrm{Na}$ atual fase dos programas de melhoramento, são grandes as dificuldades encontradas para a obtenção de progresso genético sobre o caráter rendimento de grãos, principalmente por ser este um caráter quantitativo de difícil seleção, nas primeiras gerações segregantes, pois o número de locos heteróticos é significativo. De acordo com GEADELMANN \& FREY (1975), a seleção massal pode ser praticada diretamente no caráter para o qual a melhoria é desejada ou, indiretamente, num caráter geneticamente relacionado, para tirar proveito do coeficiente de herdabilidade ou de técnicas de seleção menos onerosas. A resposta correlacionada do rendimento e de seus componentes primários pode ser um excelente critério de seleção, baseado em genes com grande efeito sobre o fenótipo.

Sendo assim, este trabalho teve por objetivo estimar os parâmetros genéticos, fenotípicos e identificar genótipos superiores, visando a recomendação de cultivares de feijão preto mais produtivas para os agricultores da região Sul do Brasil.

\section{MATERIAL E MÉTODOS}

O presente trabalho foi conduzido a campo, no ano de 1996, em Lages/SC, num cambissolo húmico distrófico, preparado de forma convencional. A adubação utilizada foi de 15,55 e $60 \mathrm{~kg} / \mathrm{ha}$ de NPK na base. A adubação de cobertura foi realizada no estádio de duas folhas trifoliadas com $70 \mathrm{~kg} / \mathrm{ha}$ de $\mathrm{N}$ (uréia). Para controle das plantas invasoras, foi aplicado o herbicida Metolachlor na dose de $2 \mathrm{~kg} / \mathrm{ha}$, logo após a semeadura, realizando-se capinas subseqüentes para controlar as invasoras que não foram eliminadas pelo herbicida. Utilizou-se o inseticida Methamidophos (Tamaron BR), para controle de Tripes do feijoeiro (C. phaseoli), pulgão (A. craccivora), cigarrinha verde (E. kraemeri) e vaquinha verde amarela $(\boldsymbol{D}$. speciosa $)$.

Trinta e dois genótipos de feijão preto foram incluídos neste trabalho, sendo 29 linhagens (AN 9021332, AN 9021361, AN 90215993, AN 9021602, AN 9021626, AN 9021697, AN 9021750, AN 9123293, CB 9021799, CB 9021830, CB 9022412, CB 9022627, Diamante Negro, FT 86-105, FT 90-1849, FT 90-1863, LP 90-98, LP 91-129, LP 92-11, LP 92-13, LP 92-16, LP 93-80, TB 94-01, TB 94-02, TB 94-03, ТВ 94-04, TB 94-62, Xamego) e 3 cultivares (Barriga Verde, IAPAR 44, Rio Tibagi) utilizadas como padrões. Todos os genótipos avaliados apresentam ramificação ereta e fechada (hábito de crescimento indeterminado) exceto os genótipos AN 9021332 e o LP 93-80 que demonstram uma ramificação aberta, abundante e prostrada (hábito de crescimento indeterminado). Tais genótipos fizeram parte do Ensaio Sulbrasileiro de Linhagens de Feijão Preto.

O delineamento experimental empregado foi de blocos casualizados, com quatro repetições por tratamento. Cada unidade experimental era constituída por duas fileiras de $5 \mathrm{~m}$ de comprimento, com cinco plantas $/ \mathrm{m}^{2}$ no espaçamento de $0,5 \mathrm{~m}$ entre linhas e 0,2m entre plantas na linha. A área útil constou de duas fileiras, descartando-se $0,5 \mathrm{~m}$ das extremidades da parcela, totalizando uma área de $4 \mathrm{~m}^{2}$.

O rendimento de grãos e componentes foram avaliados através da análise de variância. A partir da análise de variância, foram estimadas a variância genética $\left(\sigma_{G}^{2}\right)$, fenotípica $\left(\sigma_{P}^{2}\right)$ e de ambiente $\left(\sigma_{\mathrm{E}}^{2}\right)$ em nível de média, herdabilidade em nível de média $\left(h^{2}\right)$, ganho esperado com a seleção $\left(\Delta_{\mathrm{G}}\right)$ e resposta correlacionada (RC) pelas seguintes expressões apresentadas pelos autores CRUZ et al. (1997):

$$
\begin{aligned}
& \sigma_{\mathrm{P}}^{2}=\mathrm{QMG} / \mathrm{r} \quad \mathbf{h}^{2}=\sigma_{\mathrm{G}}^{2} / \sigma_{\mathrm{P}}^{2} \\
& \sigma_{\mathrm{E}}^{2}=\mathrm{QME} / \mathrm{r} \quad \Delta_{\mathrm{G}}=\mathrm{i} . \sigma_{\mathrm{Gi}} \cdot \mathrm{h}_{\mathrm{i}} \\
& \sigma_{G}^{2}=(Q M G-Q M E) / r \quad R_{(2 / 1)}=i \cdot \sigma_{G 1} \cdot h_{2} \cdot r_{g}
\end{aligned}
$$

onde: i é o diferencial de seleção estandardizado. No presente trabalho foram considerados $15 \%$ dos genótipos selecionados, sendo assim i = 1,5575; QMG é o quadrado médio dos genótipos; QME é o quadrado médio do erro; $r$ é o número de repetições; $\Delta_{\mathrm{G}}$ é o ganho genético esperado; $\sigma_{\mathrm{Gi}}$ é o desvio-padrão da variância genética aditiva do caráter $\mathrm{i} ; \mathrm{h}_{\mathrm{i}}$ é a raiz quadrada da herdabilidade, em nível de média; $\mathrm{r}_{\mathrm{g}}$ é o 
coeficiente de correlação genético entre os caracteres i e j; $\mathrm{RC}_{(2 / 1)}$ é o ganho esperado no caráter 2 na unidade em que foi avaliado, por seleção praticada no caráter 1 .

As correlações genética e fenotípica entre os caracteres foram estimadas de acordo com o procedimento relatado por FALCONER (1964):

$$
\begin{aligned}
& r_{\mathrm{g} 1,2}=\operatorname{cov}_{\mathrm{g}(1,2) /}\left(\sigma_{\mathrm{g} 1}^{2} \sigma_{\mathrm{g} 2}^{2}\right)^{1 / 2} \\
& r_{\mathrm{P} 1,2}=\operatorname{cov}_{\mathrm{P}(1,2) /}\left(\sigma_{\mathrm{P} 1}^{2} \cdot \sigma_{\mathrm{P} 2}^{2}\right)^{1 / 2}
\end{aligned}
$$

onde: $r_{\mathrm{g} 1,2}$ e $\mathrm{r}_{\mathrm{P} 1,2}$ são a correlação genética e fenotípica média, respectivamente, entre os dois caracteres; $\operatorname{cov}_{\mathrm{G}(1,2)} \mathrm{e} \operatorname{cov}_{\mathrm{P}(1,2)}$ são a covariância genética e fenotípica média, respectivamente, entre os dois caracteres.

Os dados foram submetidos à análise de variância pelo teste de $\mathrm{F}$ e as médias foram comparadas pelo teste dms de Fisher $(\mathrm{P}<0,05)$, descritos por STEEL \& TORRIE, (1960). Os parâmetros genético, fenotípico, correlações e resposta correlacionada foram obtidos a partir do programa computacional em genética e estatística elaborado por CRUZ, (1997).

\section{RESULTADOS E DISCUSSÃO}

Os resultados das análises de variância para rendimento de grãos e seus componentes estão inseridos na Tabela 1. Ocorreram diferenças significativas para os caracteres peso de mil grãos (PMG), número de legumes por planta (NLP), número de grãos por legume (NGL) e rendimento de grãos (REND) avaliados nos genótipos usados no experimento. Os coeficientes de variação oscilaram de 5,06 a 22,54\%, conferindo boa precisão às estimativas deste ensaio.

A distribuição de frequiências do caráter rendimento de grãos e seus componentes primários (NLP, NGP e PMG), pode ser visualizada na Figura 1. O gráfico relativo ao rendimento de grãos revela uma grande amplitude (1500 a 3900kg/ha) entre as classes fenotípicas. Contudo, a maior freqüência constatada foi na classe de $2700 \mathrm{~kg} / \mathrm{ha}$; o acúmulo nesta classe fenotípica foi aproximadamente de $27 \%$ do número total de valores computados para cada variável. Por outro lado, os dois extremos evidenciaram uma freqüência de apenas um valor em cada uma das classes, $(0,78 \%)$ do número de genótipos testados. Fato este que revela uma possibilidade de êxito na seleção entre linhagens com constituição genética superior aos padrões incluídos no ensaio, em relação ao caráter rendimento de grãos. Para o PMG, pode ser observado que 31 valores $(24,22 \%)$ estão incluídos na classe de 210 gramas. No entanto, para o NLP e NGL, ocorreram que 43 valores (34\%) estão na classe de 20 legumes/planta e 39 valores $(30,47 \%)$ na classe 5,2 de grão/legume, respectivamente. Portanto, fica evidente que o rendimento de grãos e o PMG seguem uma distribuição fenotípica contínua. Por outro lado, o NLP e o NGL revelaram uma distribuição fenotípica descontínua. Caracteres de distribuição contínua são governados por vários genes mendelianos, que segregam independentemente, cada qual respondendo por uma pequena parcela da variância fenotípica. Segundo CAMARGO (1995), esta distribuição contínua classifica estes caracteres (rendimento de grãos e PMG) como quantitativos. Por outro lado, o NLP e o NGL apresentaram uma distribuição fenotípica oposta, tendo o caráter NLP evidenciado uma distribuição fenotípica em direção ao limite inferior de classe, em contraste ao NGL.

As estimativas dos parâmetros

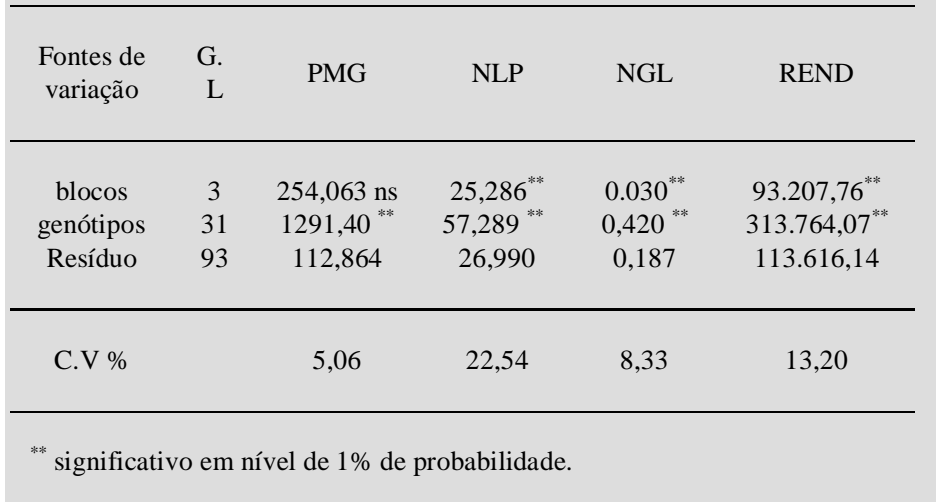
enético e fenotípico para os três componentes primários do rendimento (NLP, NGL e PMG) e para o rendimento de grãos por unidade de área estão inseridas na Tabela 3. Além das estimativas das variâncias fenotípica, de ambiente e genética, foi estimado também o coeficiente de variação genético. Segundo DUDLEY \& MOLL (1969), muitas questões sobre programas de melhoramento podem ser respondidas pelas estimativas da variância genética e da

Ciência Rural, v. 29, n. 1, 1999. 


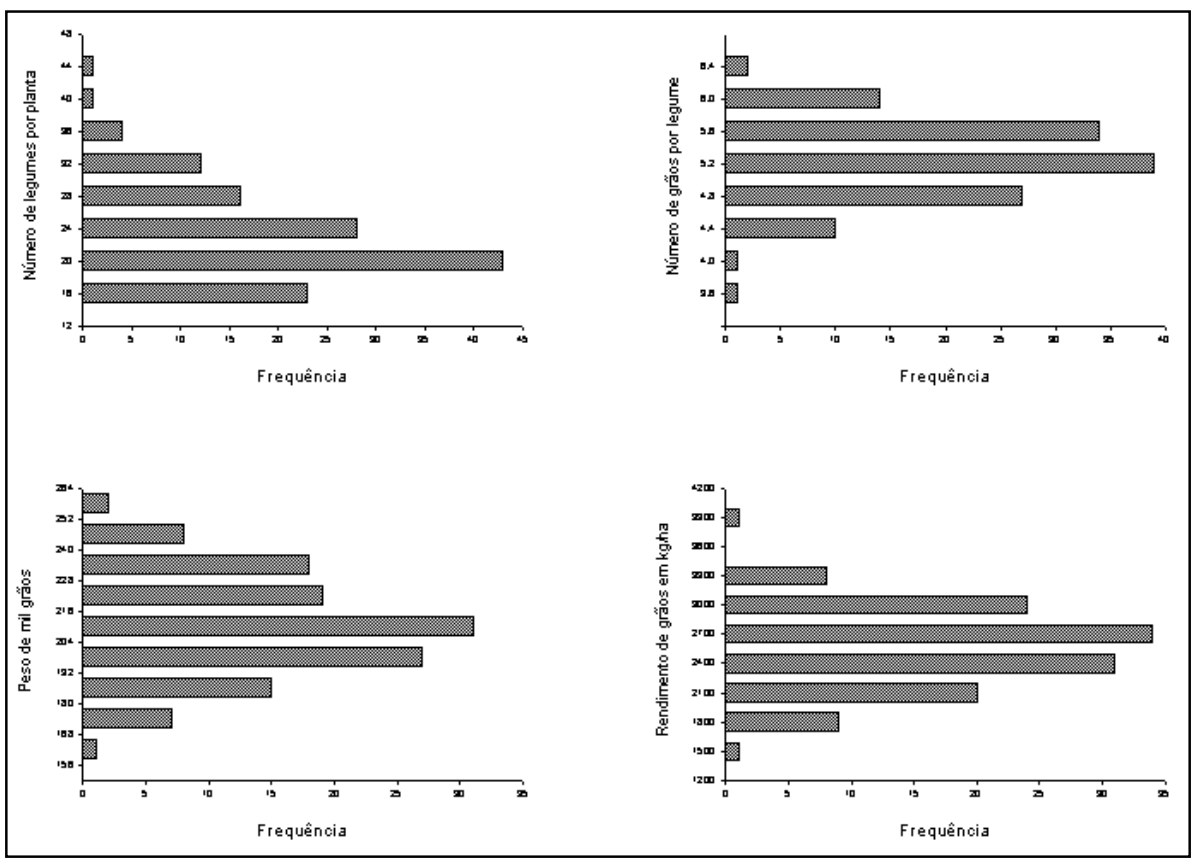

Figura 1 - Distribuição de freqüência das classes fenotípicas para o rendimento de grãos e seus componentes primários, avaliados no ano agrícola de 1996. Ensaio Sulbrasileiro de linhagens de feijão preto, Lages/SC, 1996.

gens. O alto grau de variabilidade genética (Tabela 2), observado entre as linhagens, sugere que métodos de melhoramento simples possam ser utilizados, proporcionando ganho genético considerável na seleção. Estimativas do coeficiente de herdabilidade e da razão $\mathrm{CV}_{\mathrm{G}} / \mathrm{CV}_{\mathrm{E}}$, superior à unidade para o PMG, determinam uma probabilidade de êxito para seleção neste caráter. A análise da Figura 1, confirma a situação propícia para seleção deste caráter, pois constatou-se que há constituições fenotípicas superiores para serem selecionadas nos próximos ciclos de seleção.

As estimativas das correlações genética e fenotípica entre os carac-

herdabilidade. A estimativa deste coeficiente de variação genético possibilita obter uma informação mais precisa sobre a participação do ambiente no processo de identificação de genótipos superiores, através da seleção direta no caráter em análise. Verificou-se que as estimativas de herdabilidade e da razão, entre os coeficientes de variação observados no caráter NLP, foram inferiores aos demais caracteres testados. Este fato evidencia prováveis dificuldades na seleção deste caráter. Por outro lado, o PMG apresentou o maior valor de herdabilidade no sentido amplo (91\%). Coeficientes de herdabilidade mais altos podem ser associados com maior variância genética aditiva, menor variação de ambiente e menor interação genótipo e ambiente (FEHR, 1987). A estimativa da herdabilidade para PMG é superior às relatadas na literatura por RAMALHO et al. (1979), utilizando progênies do cultivar de feijão "Pintado". Este resultado evidencia uma possibilidade de sucesso na seleção, pois o caráter será herdado de maneira expressiva de uma geração para outra. Para o PMG e o rendimento de grãos, foi observado que a estimativa de variância genética respondeu por mais de $90 \%$ e $60 \%$ da variação fenotípica, respectivamente, considerando-se a interação genótipo e ambiente nula. Por outro lado, a fração da variância de ambiente para o caráter NLP apontou uma grande influência do ambiente na constituição fenotípica destas linha- teres avaliados estão incluídas na Tabela 3. Os valores significativos das correlações genética e fenotípica para todos os caracteres variaram de 0,005 a 0,762 . Por outro lado, coeficiente de correlação igual a zero não implica falta de relação entre duas variáveis, apenas reflete a ausência de relação linear entre esses caracteres avaliados (CRUZ \& REGAZZI, 1997). Pode-se também constatar na Tabela 3, a existência de uma adequada concordância entre as estimativas das correlações genética e fenotípica, envolvendo os quatros caracteres avaliados, fato este que foi observado por RAMALHO et al. (1979). GEADELMANN \& FREY (1975) argumentam que a seleção para qualquer caráter secundário não tem valor se o desempenho deste caráter não é correlacionado com o desempenho do caráter primário. Para o caráter rendimento de grãos, as estimativas das correlações genética e fenotípica, de um modo geral, foram altamente significativas e positivas. As correlações genética e fenotípica entre os caracteres rendimento de grãos e PMG apresentaram valores positivos e superiores aos demais caracteres relacionados com o rendimento de grãos.

As estimativas das respostas correlacionadas à seleção também estão apresentadas na Tabela 3. Como as respostas correlacionadas, envolvendo rendimento de grãos e seus componentes primários (NLP, NGL e PMG), foram positivas, a seleção sendo praticada em qualquer um destes 


\begin{tabular}{|c|c|c|c|c|}
\hline \multirow[b]{2}{*}{ Parâmetros } & \multicolumn{4}{|c|}{ Caracteres Avaliados } \\
\hline & NLP & NGL & PMG & REND \\
\hline $\mathbf{s}_{\mathrm{P}}^{2}$ & 14,322 & 0,105 & 322,85 & $78.441,02$ \\
\hline $\mathbf{s}_{\mathrm{E}}^{2}$ & 6,748 & 0,046 & 28,22 & $28.404,04$ \\
\hline $\mathbf{s}_{{ }_{G}}^{2}$ & 7,575 & 0,058 & 294,64 & $50.036,98$ \\
\hline $\mathrm{h}_{\mathrm{a}}^{2}(\%)$ & 52,887 & 55,420 & 91,26 & 63,79 \\
\hline C. $\mathrm{V}_{\mathrm{G}}(\%)$ & 11,939 & 4,643 & 8,18 & 8,76 \\
\hline C. $V_{\mathrm{G}} / \mathrm{C} \cdot \mathrm{V}_{\mathrm{E}}$ & 0,530 & 0,558 & 1,6157 & 0,6636 \\
\hline
\end{tabular}

caracteres deverá contribuir de forma indireta para o aumento do rendimento de grãos. Para FEHR (1987), a efetividade da seleção indireta é aumentada quando o caráter secundário tem uma herdabilidade maior do que o caráter primário. A seleção visando ao aumento do PMG é que contribui com o maior ganho para o rendimento de grãos. Neste sentido, este ganho chegou a ser 5\% do ganho esperado com a seleção aplicada diretamente neste caráter. Este valor, relativamente alto, pode ser explicado por dois parâmetros genéticos com influência direta no valor da resposta correlacionada (variância genética do peso de mil grãos e a correlação genética entre os dois caracteres em questão). Por outro lado, as correlações envolvendo NLP e NGL foram inferiores às estimativas do caráter PMG. A seleção visando ao aumento do NLP e NGL também contribuiu com o ganho para a produtividade de grãos, porém, este ganho não

Tabela 3 - Estimativas das respostas correlacionadas à seleção, da herdabilidade no sentido amplo $\left(\mathrm{h}_{\mathrm{a}}^{2}\right)$, variância genética $\left(\mathbf{s}_{\mathrm{G}}{ }_{\mathrm{G}}\right)$, correlações genética $\left(\mathrm{r}_{\mathrm{G}}\right)$ e fenotípica $\left(\mathrm{r}_{\mathrm{P}}\right)$ e ganho genético $\left(\Delta_{\mathrm{G}}\right)$ em unidade de desvio-padrão e percentagem, obtidos no Ensaio Sulbrasileiro de feijão preto, Lages-SC, no ano agrícola de 1996.

\begin{tabular}{|c|c|c|c|c|c|c|}
\hline \multirow[b]{2}{*}{$\begin{array}{c}\text { Caráter } \\
\text { selecionado }\end{array}$} & \multirow[b]{2}{*}{$\begin{array}{l}\text { Genótipos } \\
\text { selecionados }\end{array}$} & & \multicolumn{4}{|c|}{ Respostas correlacionadas nos caracteres } \\
\hline & & & NLP & NGL & PMG & REND \\
\hline \multirow[t]{6}{*}{ NLP } & $8-1-7-31-18$ & $\mathbf{s}_{\mathrm{G}}^{2}$ & 7,57460 & 0,05820 & 294,635 & $50.036,98$ \\
\hline & & $\mathrm{r}_{\mathrm{G}}$ & 1,00 & $-0,10452$ & $-0,7615$ & 0,04158 \\
\hline & & $\mathrm{r}_{\mathrm{F}}$ & 1,00 & 0,017 & $-0,529$ & $-0,005$ \\
\hline & & $\mathrm{h}_{\mathrm{a}}^{2}$ & 52,8875 & 55,37584 & 91,2604 & 63,78931 \\
\hline & & $\Delta_{\mathrm{G}}$ & 3,11734 & $-0,02856$ & $-14,806$ & 10,53548 \\
\hline & & $\Delta_{\mathrm{G}} \%$ & 13,52 & $-0,55$ & $-7,0600$ & 0,4100 \\
\hline \multirow[t]{6}{*}{ NGL } & $6-12-1-16-29$ & $\mathbf{s}_{\mathrm{G}}^{2}$ & 7,57460 & 0,05820 & 294,63 & $50.036,98$ \\
\hline & & $\mathrm{r}_{\mathrm{G}}$ & $-0,10452$ & 1,00 & $-0,134$ & 0,28723 \\
\hline & & $r_{F}$ & 0,017 & 1,00 & $-0,119$ & 0,220 \\
\hline & & $\mathrm{h}_{\mathrm{a}}^{2} \%$ & 52,8875 & 55,37584 & 91,26 & 63,789 \\
\hline & & $\Delta_{\mathrm{G}}$ & $-0,33342$ & 0,27961 & $-2,668$ & 74,46703 \\
\hline & & $\Delta_{\mathrm{G}} \%$ & $-1,4500$ & 5,3800 & $-1,270$ & 2,920 \\
\hline \multirow[t]{6}{*}{ PMG } & $25-27-3-11-24$ & $\mathbf{s}_{\mathrm{G}}^{2}$ & 7,5746 & 0,0582 & 294,635 & $50.036,98$ \\
\hline & & $\mathrm{r}_{\mathrm{G}}$ & $-0,76154$ & $-0,13412$ & 1,00 & 0,54194 \\
\hline & & $\mathrm{r}_{\mathrm{F}}$ & $-0,529$ & $-0,119$ & 1,00 & 0,459 \\
\hline & & $\mathrm{h}_{\mathrm{a}}^{2}$ & 52,8875 & 55,37584 & 91,2604 & 63,78931 \\
\hline & & $\Delta_{\mathrm{G}}$ & $-3,11846$ & $-0,04814$ & 25,5394 & 180,37108 \\
\hline & & $\Delta_{\mathrm{G}} \%$ & $-13,53$ & $-0,9300$ & 12,170 & 7,060 \\
\hline \multirow[t]{6}{*}{ REND } & $1-12-14-13-4$ & $\mathbf{s}_{\mathrm{G}}^{2}$ & 7,5746 & 0,0582 & 294,635 & $50.036,98$ \\
\hline & & $\mathrm{r}_{\mathrm{G}}$ & 0,04158 & 0,28723 & 0,54194 & 1,00 \\
\hline & & $\mathrm{r}_{\mathrm{F}}$ & $-0,005$ & 0,220 & 0,459 & 1,00 \\
\hline & & $\mathrm{h}_{\mathrm{a}}^{2}$ & 52,8875 & 55,37584 & 91,2604 & 63,78931 \\
\hline & & $\Delta_{\mathrm{G}}$ & 0,14236 & 0,08620 & 11,5717 & 278,2579 \\
\hline & & $\Delta_{\mathrm{G}} \%$ & 0,620 & 1,66 & 5,520 & 10,9 \\
\hline
\end{tabular}

Ciência Rural, v. 29, n. 1, 1999. 
alcançou índices superiores a $1 \%$ do ganho esperado com a seleção aplicada diretamente neste caráter.

\section{CONCLUSÕES}

Os genótipos de feijão preto possuem acentuada variabilidade genética, revelando uma excelente fonte de germoplasma. A seleção direta terá êxito em qualquer um dos caracteres estudados e, para a seleção indireta, o caráter mais apropriado é o peso de mil grãos. Estimativas de parâmetros genéticos, como variância genética entre linhas puras e coeficiente de herdabilidade, no sentido amplo, auxiliam a seleção destes caracteres.

\section{AGRADECIMENTOS}

Os autores agradecem ao departamento de Fitotecnia da Universidade Federal de Pelotas (UFPel) e também à Universidade do Estado de Santa Catarina (UDESC) pelas facilidades proporcionadas para realização deste trabalho.

\section{REFERÊNCIAS BIBLIOGRÁFICAS}

CAMARGO, L.E.A. Manual de Fitopatologia. São Paulo, 1995. Cap. 24: Análise Genética da Resistência e da Patogenicidade: p. $455-469$

CARVALHO, F.I.F., UITDEWILLIGEN, W.P.M., FEDERIZZI, L.C., et al. Herdabilidade do caráter estatura de planta de trigo: estimativa através do coeficiente de regressão. Pesquisa Agropecuária Brasileira, Brasília, v. 16, p. 55-67, 1981.

CRUZ, C.D. Aplicativo computacional em genética e estatística. Viçosa: UFV, Imprensa Universitária, 1997, 442 p.
CRUZ, C.D., REGAZZI, A.J. Modelos Biométricos Aplicados ao Melhoramento Genético. 2. ed. Viçosa: UFV, Imprensa Universitária, 1997, 390 p.

DUDLEY, J.W., MOLL, R.H. Interpretation and use of estimates of heritability and genetic variances in plant breeding. Crop Science, Madison, v. 9, n. 3, p. 257-261, 1969.

FALCONER, D.S. Introduction to quantitative genetics. New York: Ronald Press, 1964, 365 p.

FEHR, W.R. Principles of cultivars development. New York: Macmillan, 1987, $536 \mathrm{p}$.

FUNDAÇÃO INSTITUTO BRASILEIRO DE GEOGRAFIA E ESTATÍSTICA. Levantamento sistemático da produção agrícola. Rio de Janeiro: IBGE/CEPAGO, 1988. 87 p.

GEADELMANN, J.L., FREY, K.J. Direct and indirect selection mass selection for grain yield in bulk oat populations. Crop Science, Madison, v. 15, p. 490-494, 1975.

JOBIM, C.I.P. Utilização de Variáveis Ambientais na Análise da Interação Genótipo $x$ Ambiente em feijão (Phaseolus vulgaris L.). Porto Alegre: UFRGS, 1990. 84 p. Dissertação (Mestrado em Fitotecnia) - Programa de Pós - graduação em Agronomia. Universidade Federal do Rio Grande do Sul. 1990 .

RAMALHO, M.A.P., SANTOS, J.B., SANTA CECÍLIA, F.C., $\boldsymbol{e}$ al. Seleção de progênies no feijão "Pintado" e estimativa dos parâmetros genéticos e fenótipicos. Ciência e Prática, Lavras, v. 3, p. 51-57, 1979.

STEEL, R.G.D., TORRIE, J.H. Principles and produceres of statistics. New York: McGraw-Hill, 473 p., 1960.

WILDNER, L.P. Manejo do solo para cultura do feijão: Principais características e recomendações técnicas. In: EPAGRI. A cultura do feijão em Santa Catarina. Florianópolis: EPAGRI, 1992, p. 83-114, 285 p.

Ciência Rural, v. 29, n. 1, 1999. 